\title{
Using multi-angle hyperspectral data to monitor canopy leaf nitrogen content of wheat
}

\author{
Xiao Song ${ }^{1,4} \cdot$ Duanyang $\mathrm{Xu}^{2} \cdot \mathrm{Li} \mathrm{He}^{1} \cdot$ Wei Feng ${ }^{1} \cdot$ \\ Yonghua Wang ${ }^{1}$ Zhijie Wang ${ }^{3}$ - Craig A. Coburn ${ }^{3}$. \\ Tiancai Guo ${ }^{1}$
}

(C) Springer Science+Business Media New York 2016

\begin{abstract}
Nitrogen $(\mathrm{N})$ content is an important factor that can affect wheat production. The non-destructive testing of wheat canopy leaf $\mathrm{N}$ content through multi-angle hyperspectral remote sensing is of great importance for wheat production and management. Based on a 2-year experiment for winter wheat in Lethbridge (Canada), Zhengzhou (China), and Kaifeng (China) growing under different cultivation practices, the authors studied the relationships between $\mathrm{N}$ content and wheat canopy spectral data in solar principal plane (SPP) and perpendicular plane (PP) at different observation angles. Modeling was conducted according to the spectrum index with the highest correlation coefficient and the corresponding observation angle. The results showed that correlation coefficient between the spectral index and canopy leaf $\mathrm{N}$ content at each observation angle of the SPP was significantly higher than that of the PP. Significant differences in the correlation coefficient were also observed at different observation angles of the same observation plane, and the correlation coefficients of angles of $-30^{\circ}$ and $-40^{\circ}$ were higher than others. A model fitted by a power function by using mND705 as independent variable at an angle of $-40^{\circ}$ in the SPP showed the highest accuracy.
\end{abstract}

Duanyang $\mathrm{Xu}$ is the Co-first author

Wei Feng

fengwei78@126.com

$\triangle$ Tiancai Guo

tcguo201@163.com

1 Henan Agricultural University/Henan Grain Crop Collaborative Innovation Center, Zhengzhou 450002, People's Republic of China

2 Institute of Geographic Science and Natural Resources Research, CAS, Beijing 100101, People's Republic of China

3 Department of Geography, University of Lethbridge, 4401 University Drive West, Lethbridge, AB TIK 3M4, Canada

$4 \quad$ Kaifeng Agriculture and Forestry Science Research Institute, Kaifeng 475004, People's Republic of China 
Keywords Multi-angle reflectance $\cdot$ Hyperspectral - Leaf nitrogen content - Wheat · Model

\section{Introduction}

Nitrogen $(\mathrm{N})$ content is an important indicator of the nutritional status of a crop. The rapid real-time acquisition of crop $\mathrm{N}$ content information is crucial for monitoring crop growth and regulating fertilization. Traditional chemical analysis techniques, such as the Kjeldahl method are often used to determine crop $\mathrm{N}$ content; however, there are several disadvantages such as the time required, high costs, and sampling requirements. In addition, only point-source information can be acquired, thus it is difficult to perform assessments on a macroscopic scale, which greatly affects the comprehensiveness, timeliness, and objectivity of agricultural decision-making (Liang et al. 2011). Therefore, the application of accurate, rapid, and economical diagnostic methods of crop $\mathrm{N}$ nutrition levels are very important for determining the correct level of fertilizer application and optimally managing nitrogenous fertilizer applications in real-time. The emergence of remote sensing technology has made the fast and non-destructive monitoring of crop $\mathrm{N}$ content possible at a large scale (Jain et al. 2007; Stroppiana et al. 2009; Ryu et al. 2009).

As an important economic crop and research model plant, the remote monitoring of wheat $\mathrm{N}$ content has been extensively studied. Many studies have used the reflectance of the corresponding wavelengths that highly related to wheat $\mathrm{N}$ content to construct the hyper-spectral index and inversion model. For example, Yang et al. (2002) successfully used Gaussian red edge width to perform the inversion of the total $\mathrm{N}$ content of a wheat canopy. Hansen and Schjoerring (2003) used near green and blue lights to establish a normalization index and further estimate the biomass and $\mathrm{N}$ content of wheat. Osborne et al. (2004) suggested that there is a close correlation between the total $\mathrm{N}$ content and canopy reflectance in winter wheat. Feng et al. (2008) suggested that a stabilized red edge or leaf area parameter is closely related to leaf $\mathrm{N}$ content parameters, including REPLe, $\mathrm{SDr}-\mathrm{SDb}$, and FD729, which were then used to monitor the leaf $\mathrm{N}$ content of wheat. Hu et al. (2009) conducted a similar research and also showed that the correlation between the REPLe of red edge parameters and agronomy components in winter wheat was better than other parameters, and was positively and highly significantly correlated with the leaf $\mathrm{N}$ content.

These studies show that the application of remote sensing techniques to estimate crop $\mathrm{N}$ nutritional status is feasible. However, these studies have used sensors to vertically collect crop canopy spectral information, and undertook modeling and inversion under the condition of isotropy diffuse reflection. In reality, the interaction between surface features and electromagnetic waves has an obvious directionality rather than isotropy. Surface reflectance and radiation characteristics will change as the observation angle varies (Asner et al. 1998; Despan et al. 1999). In this case, the observed vertical inversion model was insufficient to accurately reflect the structure, and physiological and biochemical characteristics of the crop canopy, which would affect the models application in large-scale satellite monitoring (Boyd et al. 2002; Huang et al. 2011). Compared with vertical observations, multi-angle remote sensing can monitor the target in many directions and obtain more abundant, detailed, and reliable information regarding the targeted object, which would provide a new method of quantitative remote sensing (Gao et al. 2003; Wu et al. 2010). 
However, few remote sensing inversion studies on wheat $\mathrm{N}$ nutrition through multi-angle hyperspectral data have been reported. In particular, the relative universal model of wheat canopy $\mathrm{N}$ content inversion has not been established after comprehensively considering the differences in area, variety, and cultivation practices.

Our study was based on field trials in different time periods and geographical regions, with different wheat varieties and cultivation patterns. The multi-angle and hyperspectral remote sensing data were combined to analyze the variation of spectral reflectance at different observation planes and angles. Various spectral indexes that correlated with wheat canopy leaf $\mathrm{N}$ content were compared and analyzed at different observation planes and angles to establish a multi-angle hyperspectral quantitative monitoring model of wheat $\mathrm{N}$ status. This study provides the theoretical basis and technical support for the practical application of hyperspectral remote sensing in the diagnosis of wheat $\mathrm{N}$ nutrition.

\section{Materials and methods}

\section{Experimental design}

In this study, six field trials were conducted involving different growth periods, regions, cultivars, and planting modes in China and Canada. Experiments 1-3 were conducted in 2011-2012, with $\mathrm{N}$ rate treatments for Experment 1, planting density treatments for Experiment 2, and two-factor ( $\mathrm{N}$ rate and planting density) treatments for experiment 3. Experiments 4-6 were conducted in 2012-2013, which were respectively repeatable texts of 2011-2012. The experimental design was as follows:

Experiments 1 and 4 consisted of four $\mathrm{N}$ rates $\left(0,90,180\right.$, and $360 \mathrm{~kg} \mathrm{~N}$ ha $\left.{ }^{-1}\right)$ were conducted in Science and Technology Demonstration Garden of Henan Agricultural University (latitude $34^{\circ} 51^{\prime}$, longitude $113^{\circ} 35^{\prime}$ ) in China. The soil type was fluvo-aquic soil. The five local winter wheat cultivars were planted with a planting density of $1.8 \times 10^{6}$ $\mathrm{ha}^{-1}$, a row spacing of $25 \mathrm{~cm}$, the four cultivars of Yumai 49-198 (compact type), Zhengmai 366 (loose type), Zhongyu No. 5 (loose type), and Kaimai 21 (middle type) in Experiment 1, the two cultivars of Yumai49-198 and Zhengmai 9694 (loose type) in Experiment 4. The field spectral measurements and sampling times were April 26th (flowering stage), May 6th (filling stage), May 15th (middle of filling stage), and May 26th (end of filling stage) in Experiment 1, and March 21st (jointing stage), April 5th (booting stage), April 20th (flowering stage), and May 18th (end of filling stage) in experiment 4. Other management followed local standard practices in wheat production.

Experiments 2 and 5 with four planting densities (45, 90, 180, and 360 plants ha $^{-1}$ ) were conducted at the Science and Technology Park of Kaifeng Research Academy of Agriculture and Forestry (latitude $34^{\circ} 47^{\prime}$, longitude $114^{\circ} 21^{\prime}$ ) in China. The soil type was sandy soil. The five local winter wheat cultivars were planted with a row spacing of $25 \mathrm{~cm}$, the four cultivars of Yumai 49-198, Zhengmai 366, Zhongyu No. 5, and Kaimai 21 in Experiment 2, the two cultivars of Zhoumai (compact type) and Zhongyu No. 5 in Experiments 5. The field spectral measurements and sampling times were April 24th (flowering stage), May 4th (filling stage), May 13rd (middle of filling stage), and May 24th (end of filling stage) in Experiment 2, March 22st (jointing stage), April 6th (booting stage), April 21th (flowering stage), and May 19th (end of filling stage) in Experiment 5. Other management followed local standard practices in wheat production. 
Experiments 3 and 6 were respectively conducted at the Science and Education Demonstration Park of the University of Lethbridge and the Lethbridge Department of Agriculture (Latitude $49^{\circ} 41^{\prime}$, longitude $112^{\circ} 43^{\prime}$ ) in Canada. The soil type was brown chernozemic soil. The three local spring wheat cultivars were planted, the one cultivars of Lillian in Experiment 3, the two cultivars of CDC-Go (erect type) and AC-Barrie (loose type) in Experiment 6. Experiments 3 and 6 were two-factor ( $\mathrm{N}$ rate and planting density) experiments, three planting densities $\left(90,180\right.$, and 360 plants ha $\left.{ }^{-1}\right)$ and two $\mathrm{N}$ rates $(0$, and $240 \mathrm{~kg} \mathrm{~N}^{-1}$ ) for Experiment 3, and four planting densities (90, 180, 270, and 360 plants $\left.\mathrm{ha}^{-1}\right)$ and two $\mathrm{N}$ rates $\left(0\right.$, and $\left.240 \mathrm{~kg} \mathrm{~N} \mathrm{ha}^{-1}\right)$ for Experiment 6 . The field spectral measurements and sampling times were August 5th (booting stage) and August 17th (flowering stage), August 23rd (initial filling stage) and September 8th (end of filling stage) in Experiment 3, and August 4th (booting stage) and August 18th (flowering stage) in Experiment 6. Other management followed local standard practices in wheat production.

\section{Multi-spectral data acquisition}

A FieldSpec HH $2(350-1050 \mathrm{~nm})$ spectrometer created by Analytical Spectral Device (ASD) of America was used to measure the wheat canopy spectrum in experiments 1, 2, 4, and 5. The measurement was conducted on a cloudless and windless day from 10 am to $2 \mathrm{pm}$ local time using the spectrometer fitted with a $25^{\circ}$-field-of-view fiber optic adaptor. Reflectance was recorded with a sampling interval of $1.5 \mathrm{~nm}$ and a resolution of $3.5 \mathrm{~nm}$ between 350 and $1075 \mathrm{~nm}$. The sensor was placed at a height of $1 \mathrm{~m}$ above the canopy on top of the zenith arc of a goniometer (Fig. 1). The geometric precision of the zenith arc $( \pm 0.2)$ was referenced with the help of a laser moving over the zenith arc on plane ground. The goniometer enabled directional observations of the same target and kept the distance from the spectrometer to the center of the target unchanged while moving over the target. The observation azimuth was relatively fixed as the direction of the sun, as seen from the observation point. This observational plane is referred to as the solar principal plane (SPP). The plane which is perpendicular to the SPP is referred to as the perpendicular planes (PP). The term "multi-angular" refers to observation zenith angles measured, including

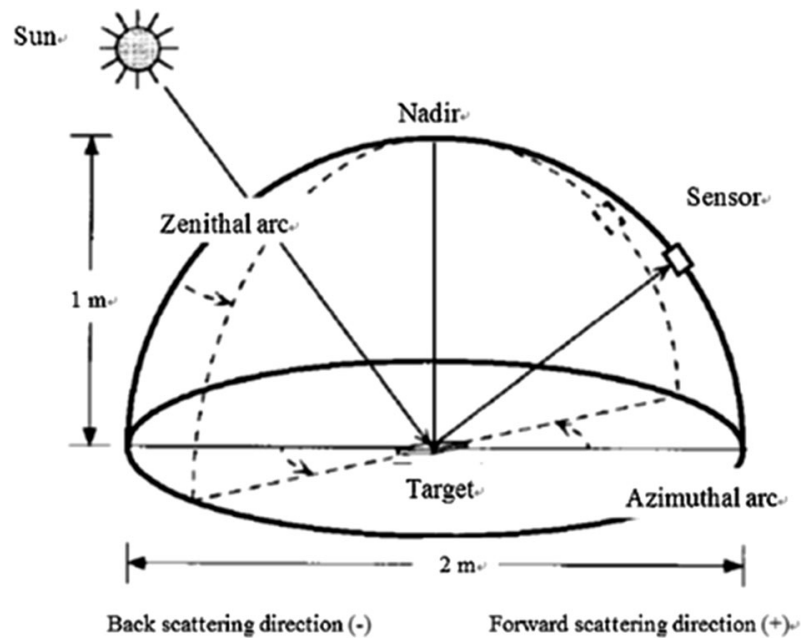

Fig. 1 Schematic diagram of measurement method 
positively and negatively angles. If the observation zenith angle was negative, it was on the same side of the sun (backward). Otherwise, it was on the opposite side of the sun (forward). The zenith angle is defined as zero at nadir position. The observation zenith angle varied from $-60^{\circ}$ to $+60^{\circ}$ at intervals of $10^{\circ}$ in each plot (i.e., $-60^{\circ},-50^{\circ},-40^{\circ}$, $-30^{\circ},-20^{\circ},-10^{\circ}, 0^{\circ}, 10^{\circ}, 20^{\circ}, 30^{\circ}, 40^{\circ}, 50^{\circ}$, and $60^{\circ}$ ). The spectral sampling interval is $1.4 \mathrm{~nm}$, repeating five times, and its average value was used as a single spectral sample of the plot area. Standard whiteboard emendation was performed timely and promptly during the measuring process. The reflectance of a standard whiteboard was 1, thus the measured spectrums of the targeted object were the dimensionless relative reflectance and relative transmittance.

A Goniometer System-2 (ULGS-2) multi-angle spectrophotometer (Fig. 2), which was invented and created by Coburn and Noble at the University of Lethbridge, was used in experiments 3 and 6 . The ULGS-2 has a unique design that addresses the requirements of an effective goniometer design and incorporates a number of technological advancements and uses a quarter circle and no ground apparatus to position the sensor as it is rotated by the central pivot at the top of the supporting structure. The arc is driven by a PC-controlled stepper motor using a gear-reduction transmission. The sensor, which carries the Upwelling (UW) sensor, is also driven by a PC-controlled stepper motor that drives the sled using a rack mounted to the arc. There are reference stops at the top and the bottom of the arc to calibrate the sled position along the arc. The measurements were conducted on a cloudless and windless day from 10 am to 2 pm local time. The ULGS-2 was programmed to acquire spectral reflectance every $10^{\circ}$ in observation zenith angles $\left(-60^{\circ}\right.$ to $\left.+60^{\circ}\right)$ in the SPP and the PP. The spectral sampling interval is $0.3 \mathrm{~nm}$, repeating ten times, and its average value was used as the spectral reflectance of the plot area. Standard whiteboard emendation was performed timely and promptly during the measuring process.

(a)

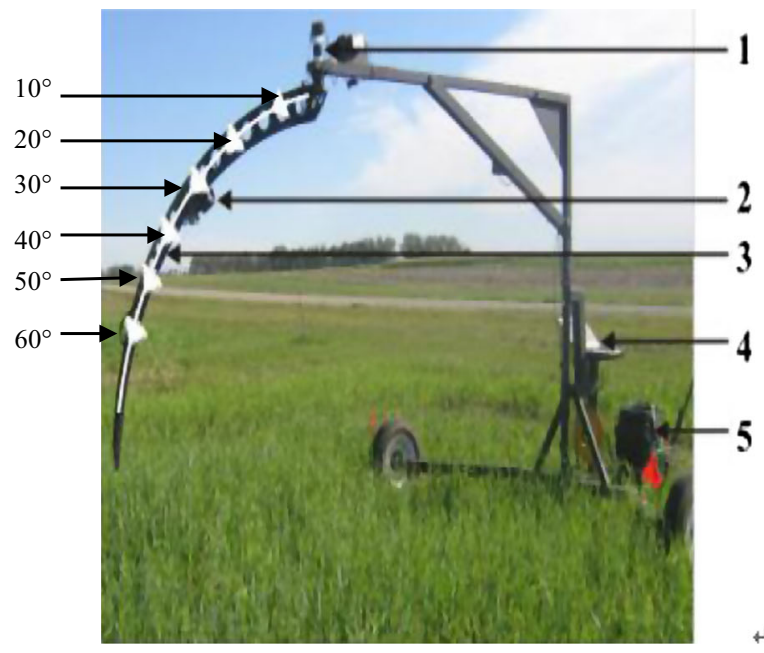

(b)

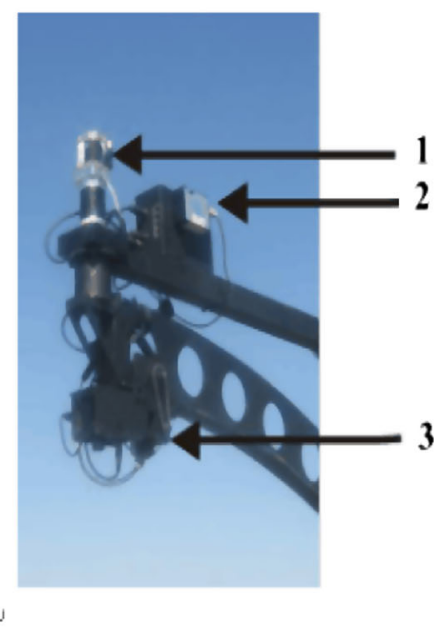

Fig. 2 The ULGS-2 Goniometer system. a 1 azimuth motor; 2 sensor seld; 32 m radius quarter arc; 4 control computer; 5 battery and inverter. b close-up. 1 azimuth motor and gear box; 2 power distribution and downwelling spectrometer; 3 sensor sled and motor drive carrying the upwelling spectrometer. Remark the angles (i.e., $10^{\circ}, 20^{\circ}, 30^{\circ}, 40^{\circ}, 50^{\circ}, 60^{\circ}$ ) are observation zenith angles in the left of $\mathbf{a}$ 


\section{Determination of wheat canopy leaf $\mathbf{N}$ content}

Samples for $\mathrm{N}$ content of wheat leaf determination were collected immediately after canopy spectral measurements. In each field, a total of 20 representative plants were selected in the jointing stages, and ten plants were selected in the flowering and filling stages. The green leaves were blanched at $105{ }^{\circ} \mathrm{C}$ for $30 \mathrm{~min}$ and then the temperature was maintained between 70 and $80^{\circ} \mathrm{C}$. After drying, grinding, and mixing, concentrated sulfuric acid was used to dissolve the sample at high temperature and convert the organic nitrogenous compounds into ammonia nitrogen. An acid standard solution was then used for titration. The $\mathrm{N}$ content was calculated according to the consumption of the standard solution.

\section{Data analysis}

In this study, reproducible tests were conducted in Lethbridge (Canada), Zhengzhou (China), and Kaifeng (China) in 2012 and 2013, and therefore we combined all of the experimental data from Canada and China to create a new data set. This was used to establish a widely applicable multi-angle remote sensing prediction model for the determination of canopy leaf $\mathrm{N}$ content. This new data set contained a total of 187 samples, of which 140 (i.e., $75 \%$ of the total samples) were randomly selected to build a wheat $\mathrm{N}$ content prediction model. The remaining 47 samples (i.e., $25 \%$ of the total samples) were used to test the model. All the data was analyzed using SPSS19.0 software.

To identify the sensitive wavelength range and the observation angle of the wheat canopy leaf $\mathrm{N}$ content, 10 high spectral indexes were chosen based on previous research results (Gamon et al. 1992; Sims and Gamon 2002; Gong et al. 2002; Feng et al. 2008; Rajeev et al. 2012), of which 5 were based on the original reflectance spectroscopy and the other 5 were based on the first-order differential processing spectral data. The formula is shown in Table 1. On this basis, a correlation analysis was used to calculate the correlation coefficients of the wheat leaf $\mathrm{N}$ content and different hyperspectral indexes observed at different observation angles in SPP and PP. The spectral index with the highest correlation coefficient and its corresponding observation angle were selected for modeling.

Table 1 The algorithm and references of different spectral parameters

\begin{tabular}{lll}
\hline Spectral parameter & Algorithm ${ }^{\mathrm{a}}$ & References \\
\hline mND705 & $\left(R_{750}-R_{705}\right) /\left(R_{750}+R_{705}-2 \times R_{445}\right)$ & Sims and Gamon (2002) \\
ND680 & $\left(R_{800}-R_{680}\right) /\left(R_{800}+R_{680}\right)$ & Sims and Gamon (2002) \\
PRI & $\left(R_{531}-R_{570}\right) /\left(R_{531}+R_{570}\right)$ & Gamon et al. (1992) \\
GNDVI & $\left(R_{750}-R_{550}\right) /\left(R_{750}+R_{550}\right)$ & Rajeev et al. (2012) \\
NDCI & $\left(R_{762}-R_{527}\right) /\left(R_{762}+R_{527}\right)$ & Rajeev et al. (2012) \\
SDr/SDb & SDr/SDb & Gong et al. (2002) \\
SDr-SDb & SDr-SDb & Feng et al. (2008) \\
SDr-SDy & SDr-SDy & Feng et al. (2008) \\
SDr & SDr & Feng et al. (2008) \\
Dr & Dr & Feng et al. (2008) \\
\hline
\end{tabular}

SDr is the sum of the first order derivative values within the red edge $(680-760 \mathrm{~nm}), \mathrm{SDb}$ is the sum of the first order derivative values within the blue edge $(490-530 \mathrm{~nm})$, SDy is the sum of the first order derivative values within the yellow edge $(560-640 \mathrm{~nm})$; and Dr is the maximum value of the first order derivative values within the red edge $(680-760 \mathrm{~nm})$

${ }^{a} \mathrm{R}$ denotes reflectance 
For modeling, ten types of equation (i.e., linear, logarithmic, reciprocal, quadratic, cubic function, composite function, power function, $\mathrm{S}$ function, growth function and exponential function) were selected. Wheat canopy leaf $\mathrm{N}$ content was set as the dependent variable, and the value of the spectral index with the highest correlation coefficient, observed at the corresponding observation angle, was set as the independent variable for modeling. The most appropriate model was determined after comparing the $\mathrm{R}^{2}$ values of various prediction models. On this basis, the 47 verification samples were used for testing the most appropriate model. Four indexes (i.e., root mean square error (RMSE), average relative error (RE), $\mathrm{R}^{2}$, and the slope of the predicted and actual value linear regression), were used to evaluate the precision and accuracy of the models.

$$
\begin{gathered}
R M S E=\sqrt{\frac{1}{n} \times \sum_{i=1}^{n}(P i-O i)^{2}} \\
R E(\%)=\sqrt{\frac{1}{n} \times \sum_{i=1}^{n}\left(\frac{P i-O i}{O i}\right)^{2}} \times 100 \%
\end{gathered}
$$

where $P i$ and $O i$ are the predicted and observed values, respectively, and $n$ is the number of samples. $R E(\%)$ is the relative difference between the predicted and observed data. The prediction is considered excellent when $R E<10 \%$, good when $R E=10-20 \%$, fair when $R E=20-30 \%$, and poor when $R E>30 \%$ (Jamieson et al. 1991; Zhu et al. 2006).

\section{Results}

\section{Canopy spectral characteristics of wheat observed at different angles and in different planes}

The wheat canopy reflectance spectrum at the N0 level in the filling stage in experiment 1 (May 6, 2012, Zhengzhou, China) was used as an example to illustrate the response characteristics of the wheat canopy reflectance spectrum at different angles and in different planes. According to Figs. 3 and 4, although typical vegetation spectral features were

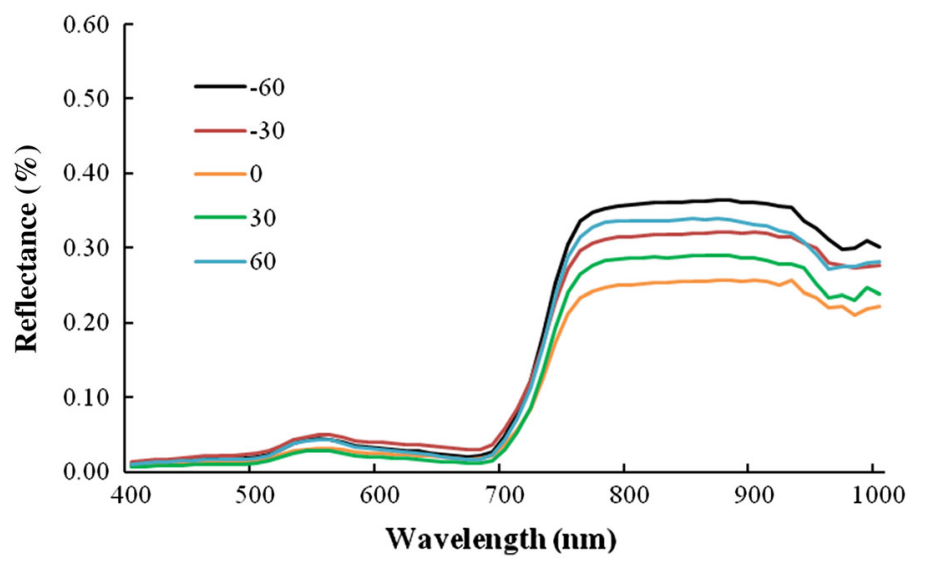

Fig. 3 Canopy spectral characteristics of wheat observed at different angles and in SPP 


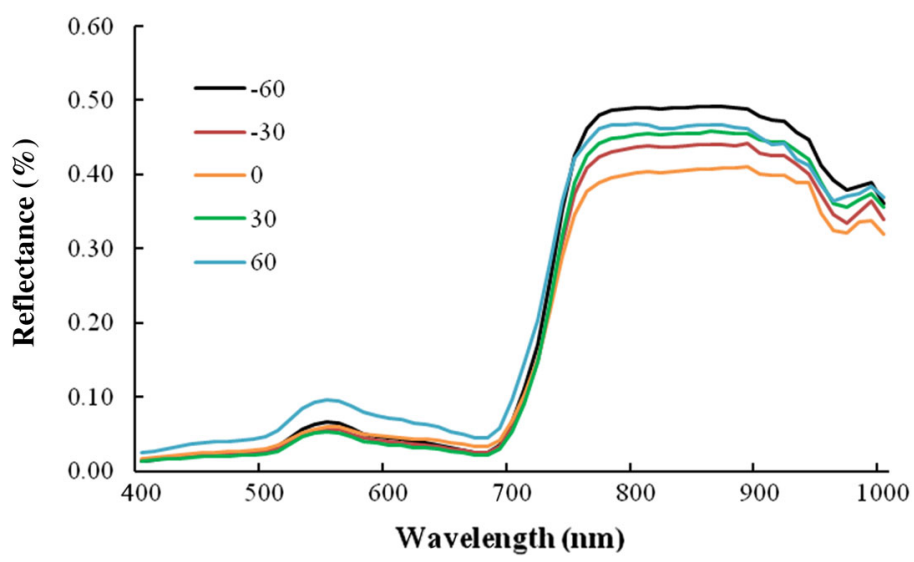

Fig. 4 Canopy spectral characteristics of wheat observed at different angles in the PP

observed in SPP and PP, some obvious differences were apparent. The reflectance of green light (510-570 nm) and near infrared (780-900 nm) in PP was significantly higher than in SPP. This may be related to the proportion of shadow components of the viewing field in SPP, which changed dramatically with the observed zenith angle.

To further investigate the differences in the wheat canopy reflectance spectrum in different observation planes and at different angles, four wavelengths [i.e., $450 \mathrm{~nm}$ (blue), $560 \mathrm{~nm}$ (green), $670 \mathrm{~nm}$ (red) and $860 \mathrm{~nm}$ (near infrared)], which are commonly used in the establishment of vegetation indexes and the corresponding inversion indexes (Jain et al. 2007; Stroppiana et al. 2009; Ryu et al. 2009; Yang et al. 2002; Hansen and Schjoerring, 2003; Xue et al. 2004), were chosen to analyze the changes of reflectance in different observation planes and at different angles. According to Fig. 5, the four representative bands (450, 560, 670 and $860 \mathrm{~nm}$ ) were analyzed under different observation zenith angles in the SPP and PP. As mentioned above, negative observation zenith angles were in the backscattering direction (azimuth angle is $0^{\circ}$ ), and positive view zenith angles were in the forward scattering direction (azimuth angle is $180^{\circ}$ ). The reflectance values changed with observation zenith angles in the SPP and PP. The spectral reflectance values of canopies showed similar tendencies at the four bands with higher values in the backscattering direction than in the forward direction in the SPP. The curves exhibited a "spoon shape", first increasing then decreasing from the backscattering direction to the forward scattering direction at 450, 560 and $670 \mathrm{~nm}$. Maximum values were obtained at $-40^{\circ}$ for 450 and $560 \mathrm{~nm}$, and at $-30^{\circ}$ for $670 \mathrm{~nm}$. This was due to the proportion of upper canopy components viewed by the spectrometer decreasing and the proportion of bottom canopy components increasing when the sensor was moved from the backscattering direction to the forward scattering direction in the visible region, which lead to canopy reflectance showed a decreasing trend (García-Haro and Sommer, 2002). Compared with SPP, the spectral reflectance curves of canopies showed different at 450, 560 and $670 \mathrm{~nm}$ in the PP, which presented an irregular change. Moreover, reflectance showed a typical asymmetric "bowl-shape" at $860 \mathrm{~nm}$ and a smaller difference between the backscattering and forward scattering directions in the SPP and PP. That may be because the reflectance of $860 \mathrm{~nm}$ bands are relatively high, and are almost equal with their transmittance, so multiple scattering makes their reflectance is insensitive to observation zenith angles (Wang et al. 

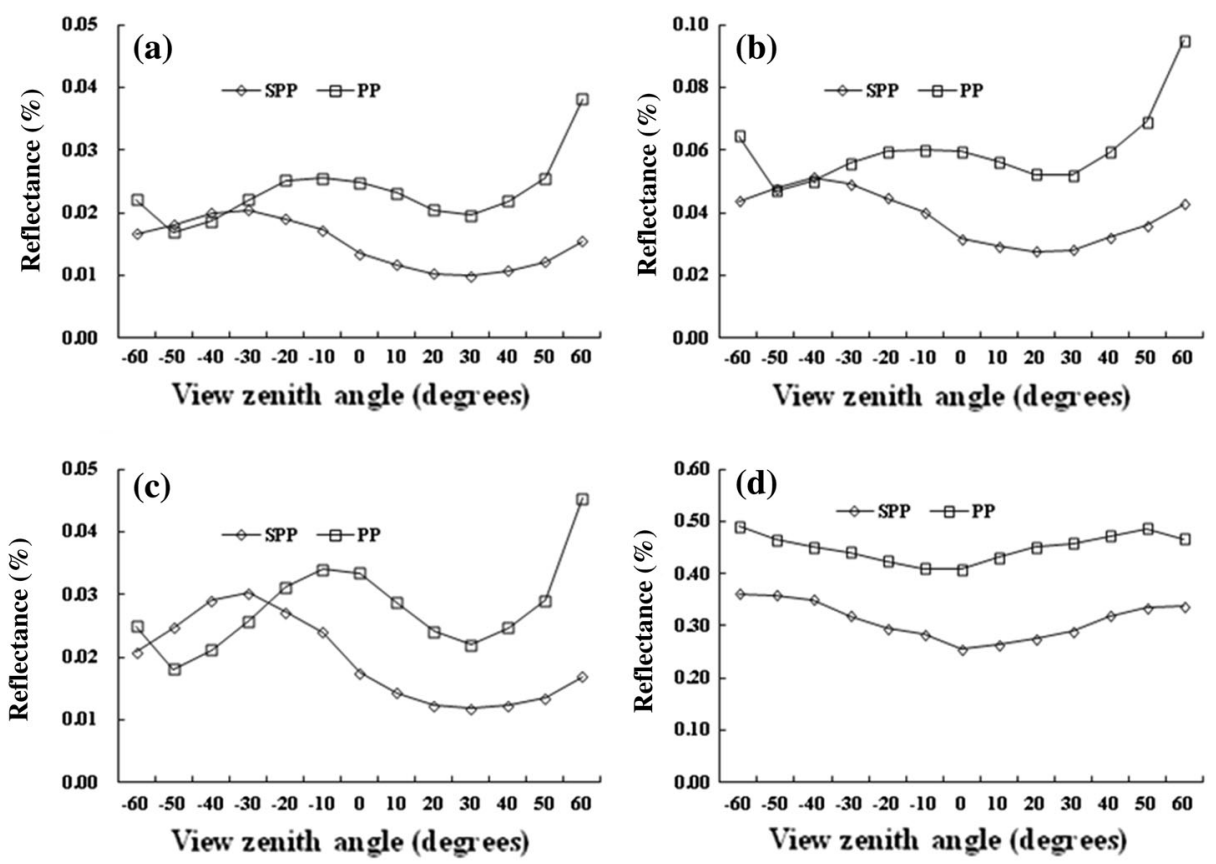

Fig. 5 The variety of reflectance of the typical wavelengths observed in different planes and at different angles. a $450 \mathrm{~nm}$; b $560 \mathrm{~nm}$; $670 \mathrm{~nm}$; d $860 \mathrm{~nm}$

2012). Another, reflectance observed in the PP was higher than that in SPP in the different view zenith angles at all four wavelength, except for the observation angle from $-40^{\circ}$ to $-50^{\circ}$ at 450 and $560 \mathrm{~nm}$, from $-30^{\circ}$ to $-50^{\circ}$ at $670 \mathrm{~nm}$. In a word, the differences of reflectance observed in different planes and at different angles may result in differences of the model and the accuracy of the spectral indexes monitoring physiological and biochemical components of vegetation.

\section{Correlation between different spectral indexes and wheat canopy leaf $\mathbf{N}$ content in different observation planes and at different angles}

As expected, different wheat cultivars, growth stages and $\mathrm{N}$ treatments, together with different sites and years, caused considerable variation in the canopy leaf $\mathrm{N}$ content (Table 2). The most variation of canopy leaf $\mathrm{N}$ content [coefficient of variation $(\mathrm{CV})=39.2 \%$ ] was in Canada and the smallest variable $(\mathrm{CV}=9.6 \%)$ was at the filling stage. The variations of canopy leaf $\mathrm{N}$ content in each datasets were suitable for developing and validating regression models between spectral indexes and wheat canopy leaf $\mathrm{N}$ content. However, variances were homogeneous across years, locations and growth stages. This prompted us to consider that canopy leaf $\mathrm{N}$ content could be remotely estimated in one data set in different experimental conditions.

Another, the performance of spectral indexes varied with different N status (Cao 2013). We picked out two spectral indexes (mND705 and ND680) from the ten spectral indexes in Table 1 which are commonly used in the version of wheat canopy $\mathrm{N}$ content, and took them for example to study variety of spectral indexes at different experiment conditions 
Table 2 Descriptive statistics of wheat canopy leaf $\mathrm{N}$ content in different years, sites, and growth stages

\begin{tabular}{|c|c|c|c|c|c|c|}
\hline & $\mathrm{N}$ & Min & $\operatorname{Max}$ & Mean & SD & $\mathrm{CV}(\%)$ \\
\hline 2011-2012 & 63 & 0.589 & 4.175 & 3.379 & 0.545 & 16.1 \\
\hline 2012-2013 & 77 & 0.652 & 4.064 & 3.14 & 1.009 & 32.1 \\
\hline China & 55 & 0.589 & 4.15 & 3.292 & 0.835 & 25.4 \\
\hline Canada & 85 & 0.611 & 4.175 & 3.002 & 1.176 & 39.2 \\
\hline Jointing stage & 30 & 2.441 & 4.064 & 3.009 & 0.308 & 10.2 \\
\hline Booting stage & 33 & 2.805 & 4.175 & 3.273 & 0.382 & 11.7 \\
\hline Flowering stage & 25 & 2.794 & 3.599 & 3.092 & 0.371 & 12.0 \\
\hline Filling stage & 26 & 2.362 & 3.343 & 2.547 & 0.244 & 9.6 \\
\hline End of filling stage & 26 & 0.589 & 1.923 & 1.154 & 0.33 & 28.6 \\
\hline All stages combined & 140 & 0.589 & 4.175 & 2.575 & 0.891 & 34.6 \\
\hline
\end{tabular}

Table 3 Descriptive statistics of spectral indices for mND705 and ND680 in different years, sites, and growth stages

\begin{tabular}{lllllll}
\hline & N & Min & Max & Mean & SD & CV (\%) \\
\hline mND705 & & & & & & \\
2011-2012 & 63 & 0.478 & 0.840 & 0.738 & 0.079 & 10.7 \\
2012-2013 & 77 & 0.086 & 0.871 & 0.638 & 0.218 & 34.1 \\
China & 55 & 0.086 & 0.871 & 0.729 & 0.093 & 12.7 \\
Canada & 85 & 0.246 & 0.723 & 0.478 & 0.121 & 28.1 \\
Gointing stage & 30 & 0.184 & 0.856 & 0.677 & 0.193 & 28.4 \\
Booting stage & 33 & 0.179 & $0.549 \mathrm{~s}$ & 0.491 & 0.112 & 22.9 \\
Flowering stage & 25 & 0.154 & 0.723 & 0.469 & 0.180 & 38.3 \\
Filling stage & 26 & 0.086 & 0.871 & 0.592 & 0.200 & 33.8 \\
End of filling stage & 26 & 0.154 & 0.723 & 0.450 & 0.176 & 39.0 \\
All stages combined & 140 & 0.086 & 0.871 & 0.696 & 0.270 & 38.9 \\
ND680 & & & & & & \\
2011-2012 & 63 & 0.944 & 1.421 & 1.319 & 0.098 & 7.4 \\
2012-2013 & 77 & 0.320 & 1.425 & 1.172 & 0.274 & 23.4 \\
China & 55 & 0.488 & 1.425 & 1.282 & 0.133 & 10.4 \\
Canada & 85 & 0.320 & 0.881 & 0.650 & 0.184 & 31.4 \\
Jointing stage & 30 & 0.566 & 1.425 & 1.239 & 0.238 & 19.2 \\
Booting stage & 33 & 0.242 & 1.233 & 0.768 & 0.282 & 36.7 \\
Flowering stage & 25 & 0.174 & 0.631 & 0.427 & 0.141 & 33.1 \\
Filling stage & 26 & 0.320 & 1.416 & 1.110 & 0.352 & 31.7 \\
End of filling stage & 26 & 0.174 & 0.684 & 0.432 & 0.155 & 35.9 \\
All stages combined & 140 & 0.320 & 1.425 & 0.767 & 0.432 & 44.2 \\
\hline
\end{tabular}

(Table 3). Table 3 showed the varieties of mND705 and ND680 across years, locations and growth stages at $0^{\circ}$ observation zenith angle in the SPP with CV of. 10.7-39.0\% for mND705 and 7.4-44.2\% for ND680. 


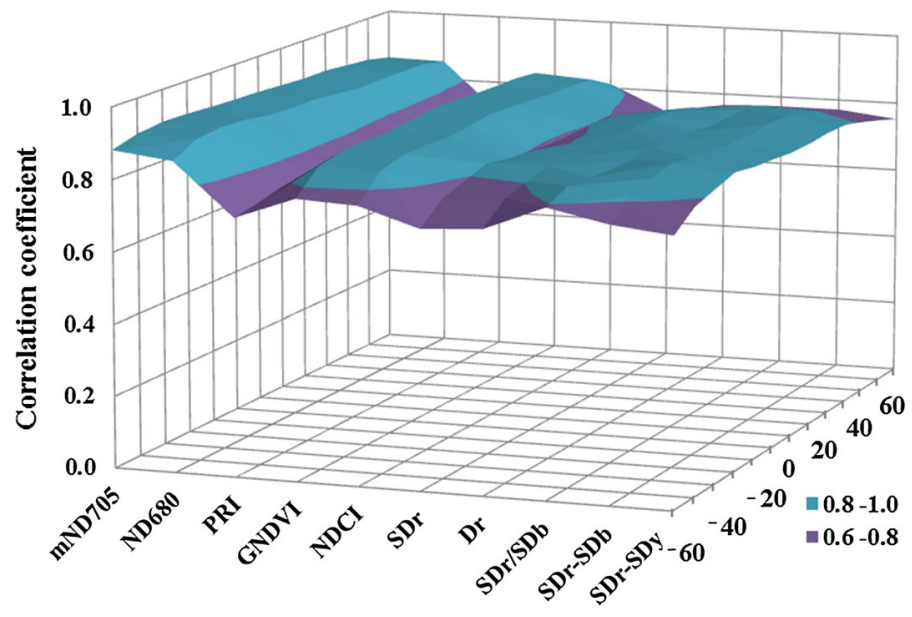

Fig. 6 The correlation between each spectral index and the canopy nitrogen content at different observation angles in the SPP

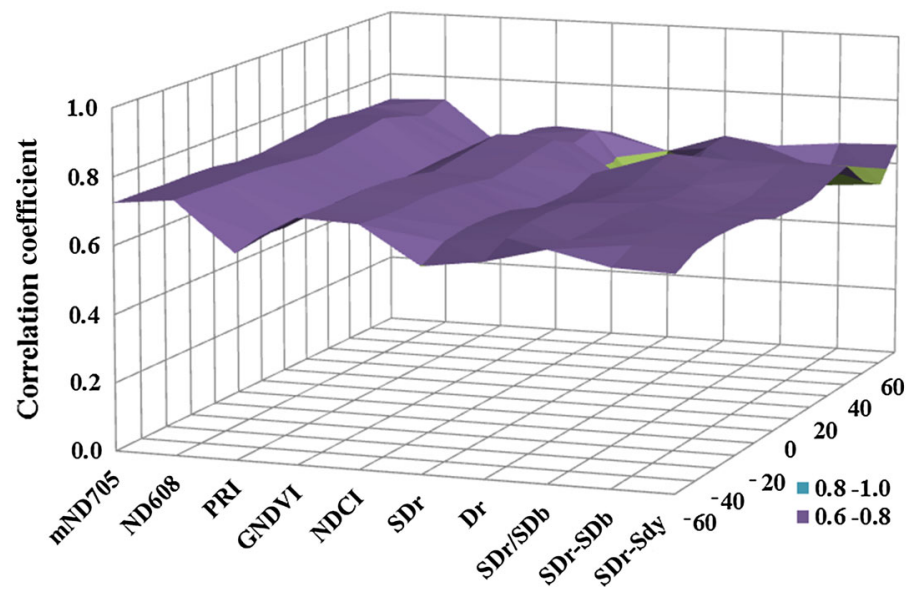

Fig. 7 The correlation between each spectral index and the canopy nitrogen content at different observation angles in the PP

To explore the relationships between the spectral indexes and canopy leaf $\mathrm{N}$ content, the ten spectral index values were calculated in different observation planes and at different angles. On this basis, the correlation coefficients between each spectral index and the wheat canopy leaf $\mathrm{N}$ content in different observation planes and at different angles were studied, and three-dimensional figures were then constructed (Figs. 6, 7). As shown in Figs. 6 and 7, the correlation coefficient between each spectral index and the wheat canopy leaf $\mathrm{N}$ content in SPP was significantly higher than in PP at different observation angles, and had not an obvious change in the PP. Considering the performances of the various spectral indexes, the correlation between mND705/ND680 and the wheat canopy leaf $\mathrm{N}$ content was significantly higher than the other indexes. For the same observation plane, the correlation coefficient of the spectral index and the wheat canopy leaf $\mathrm{N}$ content was also significantly different (He et al. 2015). Taking SPP as an example, the average correlation 


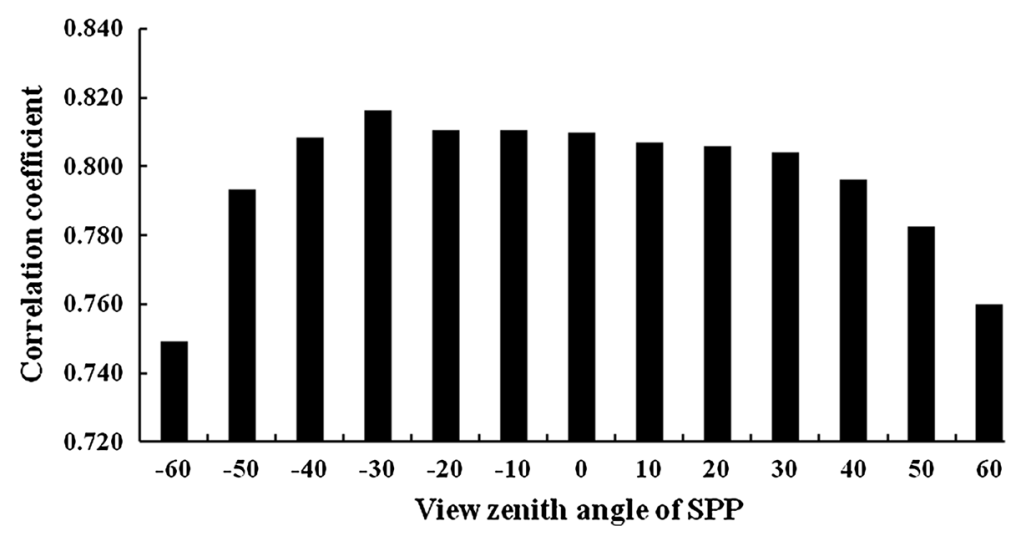

Fig. 8 The mean value of the spectral index correlation coefficient at different observation angles in the SPP

coefficient between the spectral indexes and the wheat canopy leaf $\mathrm{N}$ content was higher for angles ranging from $-40^{\circ}$ to $-20^{\circ}$, with the highest average correlation coefficient observed at an angle of $-30^{\circ}$ (Fig. 8). So, above results showed that mND705 and ND680 were potential for estimating canopy leaf $\mathrm{N}$ content of wheat, and the optimal angle was within the scope from $-40^{\circ}$ to $-20^{\circ}$.

\section{The inversion model of wheat canopy leaf $\mathbf{N}$ content}

On the basis of the correlation coefficients between the spectral indexes and the wheat canopy leaf N content in SPP and PP at different observation angles, mND705 and ND680 were chosen to develop an inversion model at observation angles of $-40^{\circ}$ and $-30^{\circ}$. To assess the goodness and the accuracy of different fitting models, three indicators $\left(\mathrm{R}^{2}\right.$, RMSE, and RE) were used to conduct a comprehensive assessment. According to Table 4, the mND705 value observed in the SPP at an angle of $-40^{\circ}$ was set as the independent variable, and the models fitted by the cubic and power functions performed best, with $\mathrm{R}^{2}$ of 0.823 , RMSE of 0.365 and RE of $14.3 \%$ for the cubic function and $\mathrm{R}^{2}$ of 0.880 , RMSE of 0.363 and RE of $14.5 \%$ for the power function. As indicated that mND705 developed based on ND705 by incorporating reflectance at $445 \mathrm{~nm}$ waveband (Sims and Gamon 2002) was more appropriate predictor of wheat canopy leaf $\mathrm{N}$ content than other spectral indexes, and had strong capacity of reducing effects of experiment conditions on monitoring model. Another, the better performance of mND705 may be based largely in the rededge (Broge and Leblanc, 2000). Li et al. (2012) proved red-edge indices were more sensitive and robust in deriving plane N-status. Feng et al. (2014) also indicated that rededge indices were stable and powerful enough for monitoring leaf $\mathrm{N}$ content across different sites, times, cultivars and phonological.

\section{Verification of the wheat canopy leaf $\mathbf{N}$ content inversion model}

On the basis of the two selected models with the best fitting goodness and accuracy based on 47 verification points, mND705 values calculated in SPP at an angle of $-40^{\circ}$ were used to predict the leaf $\mathrm{N}$ content of the wheat canopy. The predicted value was then compared with the actual value. A comprehensive comparison was performed among the RMSE, RE, 


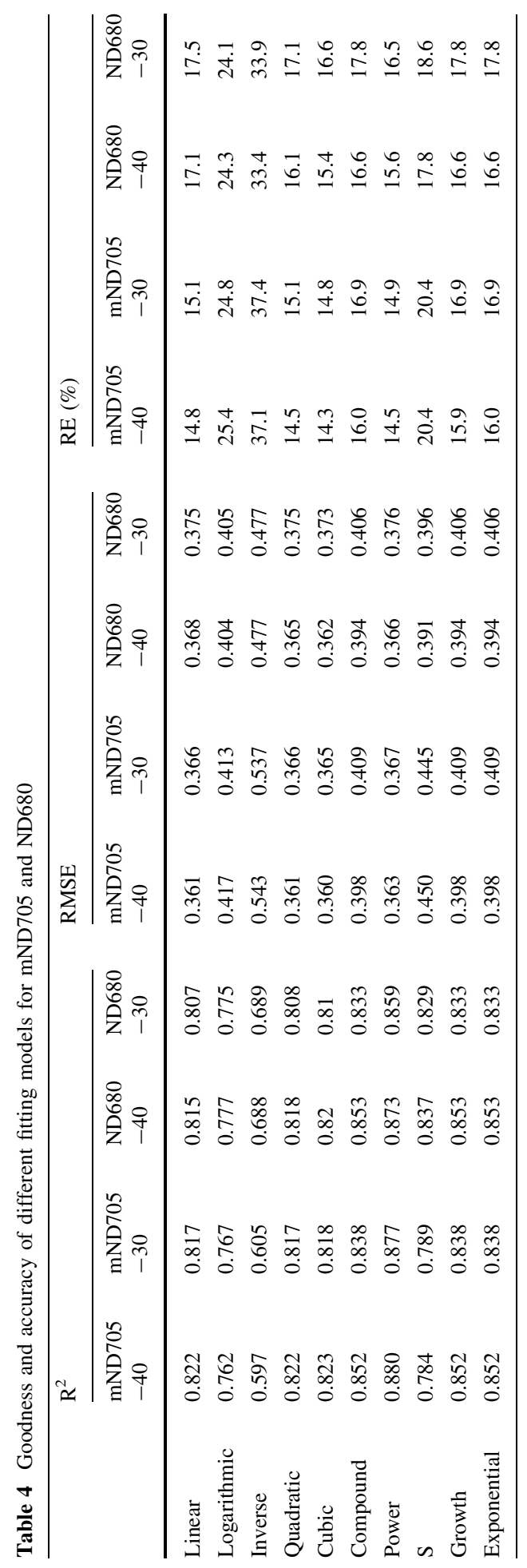



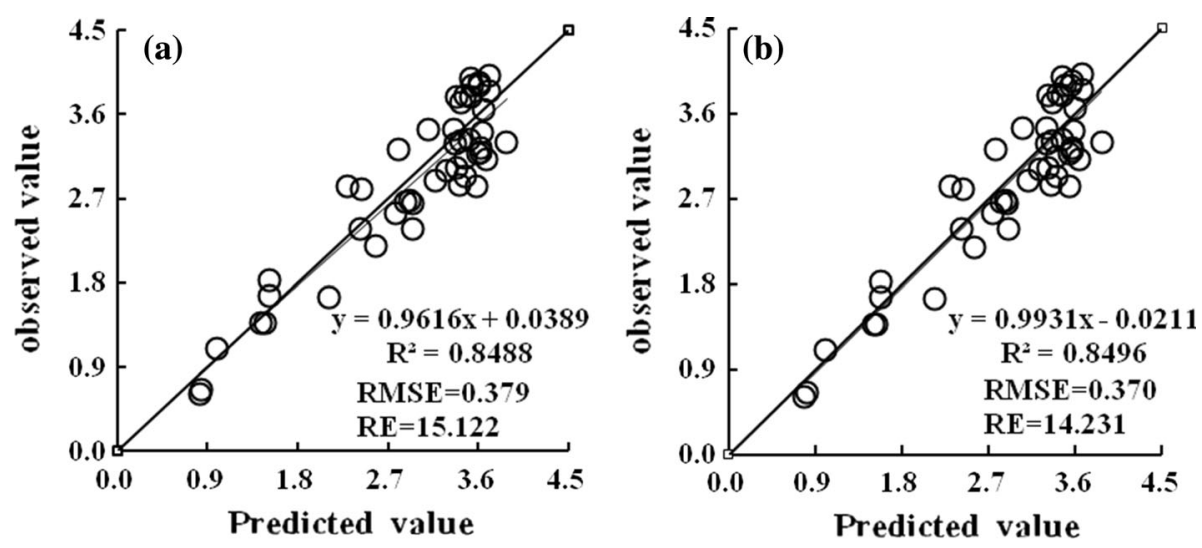

Fig. 9 Model validation: a cubic function, b power function

and $\mathrm{R}^{2}$ indicators, and the slope of the predicted value and the actual value of the linear regression (Fig. 9). It was observed that both models displayed better stability. If the mND705 value observed at an angle of $-40^{\circ}$ was set as an independent variable, using a power function to build the model would have a better validation effect.

\section{Conclusion}

In this study, 2-year wheat field trial data from different regions, with different cultivation practices, and using different cultivars was used to comprehensively analyze the differences of canopy reflectance in different planes and at different angles, and then to construct a canopy leaf $\mathrm{N}$ content inversion model. Three indicators (i.e., $\mathrm{R}^{2}$, RMSE and RE), were chosen to comprehensively evaluate the model. Significant differences were observed in the correlation between wheat canopy leaf $\mathrm{N}$ contents and spectral indicators in different planes and at different angles. The correlation in SPP was significantly higher than in PP. The strongest correlations were found in mND705 and ND680 at angles of $-40^{\circ}$ and $-30^{\circ}$ in SPP, and the models fitted by cubic and power functions with mND705 value at an angle of $-40^{\circ}$ in SPP as independent variable performed best. However, the power function performed better after verifying the RMSE, RE, $\mathrm{R}^{2}$, and the slope of the predicted and actual value linear regressions. Considering the impacts of the test fields and cultivars, the accuracy of our study was not as high as in previous studies that conducted in a fixed field under a single condition. Despite this, our study provides a good reference for monitoring for wheat $\mathrm{N}$ content at large-scale.

Acknowledgments This research was supported by the Modern Agricultural Technical System of China Special Foundation for Agro-scientific Research in the Public Interest (201203096, 201303109). The authors are grateful to Henan Agricultural University in China for funding and guidance and thank the University of Lethbridge for the use of the Goniometer System version 2.0 (ULGS-2.0) and technical guidance.

\section{References}

Asner, G. P., Braswell, B. H., Schimel, D. S., \& Wessman, C. A. (1998). Ecological research needs from multiangle remote sensing data. Remote Sensing of Environment, 63, 155-165. 
Boyd, D. S., Foody, G. M., \& Ripple, W. J. (2002). Evaluation of approaches for forest cover estimation in the Pacific Northwest, USA, using remote sensing. Applied Geography, 22(4), 375-392.

Broge, N. H., \& Leblanc, E. (2000). Comparing prediction power and stability of broadband and hyperspectral vegetation indices for estimation of green leaf area index and canopy chlorophyll density. Remote Sensing of Environment, 76, 156-172.

Cao, Q., Miao, Y. X., Wang, H. Y., Huang, S. Y., Cheng, S. S., Khosla, R., et al. (2013). Non-destructive estimation of rice plant nitrogen status with crop circle multispectral active canopy sensor. Field Crop Research, 154, 133-144.

Despan, D., Bedidi, A., \& Cervelle, B. (1999). Bidirectional reflectance of rough bare soil surfaces. Geophysical Research Letters, 26(17), 2777-2780.

Feng, W., Guo, B. B., Wang, Z. J., He, L., Song, X., Wang, Y. H., \& Guo, T. C. (2014). Measuring leaf nitrogen concentration in winter wheat using double-peak spectral reflection remote sensing data. Field Crops Research., 159, 43-52.

Feng, W., Yao, X., Zhu, Y., Tian, Y. C., \& Cao, W. X. (2008). Monitoring leaf nitrogen concentration by hyperspectral remote sensing in wheat. European Journal of Agronemy, 28, 394-404.

Gamon, J. A., Penuelas, J., \& Field, C. B. (1992). A narrow-waveband spectral index that tracks diurnal changes in photosynthetic efficiency. Remote Sensing of Environment, 41, 35-44.

Gao, F., Schaaf, C. B., \& Strahler, A. H. (2003). Detecting vegetation structure using a kernel-based BRDF model. Remote Sensing of Environment, 86, 198-205.

García-Haro, F. J., \& Sommer, S. (2002). A fast canopy reflectance model to simulate realistic remote sensing scenarios. Remote Sensing of Environment, 81, 205-227.

Gong, P., Pu, R., \& Heald, R. C. (2002). Analysis of in situ hyperspectral data for nutrient estimation of giant sequoia. International Journal of Remote Sensing, 23, 1827-1850.

Hansen, P. M., \& Schjoerring, J. K. (2003). Reflectance measurement of canopy biomass and nitrogen status in wheat crops using normalized difference vegetation indices and partial least squares regression. Remote Sensing of Environment, 86(4), 542-553.

He, L., Zhang, H. Y., Zhang, Y. S., Song, X., Feng, W., Kang, G. Z., et al. (2015). Estimating canopy leaf nitrogen concentration in winter wheat based on multi-angular hyperspectral remote sensing. European Journal of Agronomy, 73, 170-185.

Hu, H., Bai, Y. L., Yang, L. P., Lu, Y. L., Wang, L., Wang, H., \& Kong, Q. B. (2009). Red edge parameters of winter wheat canopy under different nitrogen levels. Plant Nutrition and Fertilizer Science, 15(6), 1317-1323. (in Chinese).

Huang, W. J., Wang, Z. J., Huang, L. S., Lamb, D. W., Ma, Z. H., Zhang, J. C., et al. (2011). Estimation of vertical distribution of chlorophyll concentration by bi-directional canopy reflectance spectra in winter wheat. Precision Agriculture, 12(2), 165-178.

Jain, N., Ray, S. S., Singh, J. P., \& Panigrahy, S. (2007). Use of hyperspectral data to assess the effects of different nitrogen applications on a potato crop. Precision Agriculture, 8(4/5), 225-239.

Jamieson, P. D., Porter, J. R., \& Wilson, D. R. (1991). A test of the computer simulation model ARCWHEAT1 on wheat crops grown in New Zealand. Field Crop Research, 27, 337-350.

Li, F., Mistele, B., Hu, Y. C., Yue, X. L., Yue, S. C., Miao, Y. X., et al. (2012). Remotely estimating aerial N status of phenologically differing winter wheat cultivars grown in contrasting climatic and geographic zones in China and Germany. Field Crops Research., 138, 21-32.

Liang, L., Yang, M. H., Deng, K. D., Zhang, L. P., Lin, H., \& Liu, Z. X. (2011). A new hyperspectral index for the estimation of nitrogen contents of wheat canopy. Acta Ecologica Sinica, 31(21), 6594-6605.

Osborne, S. L., Sehepers, J. S., \& Schlemmer, M. R. (2004). Using multi-spectral imagery to evaluate corn grown under nitrogen and drought stressed conditions. Plant Nutrition, 27(11), 1917-1929.

Rajeev, R., Chopra, U. K., Sahoo, R. N., Singh, A. K., \& Pradhan, S. (2012). Assessment of plant nitrogen stress in wheat Triticum aestivum L. through hyperspectral indices. International Journal of Remote Sensing, 20, 6342-6360.

Ryu, C., Suguri, M., \& Umeda, M. (2009). Model for predicting the nitrogen content of rice at panicle initiation stage using data from airborne hyperspectral remote sensing. Biosystems Engineering, 104(4), 465-475.

Sims, D. A., \& Gamon, J. A. (2002). Relationships between leaf pigment content and spectral reflectance across a wide range of species, leaf structures and developmental stages. Remote Sensing of Environment, $81,337-354$.

Stroppiana, D., Boschetti, M., Brivio, P. A., \& Bocchi, S. (2009). Plant nitrogen concentration in paddy rice from field canopy hyperspectral radiometry. Field Crops Research, 111, 119-129.

Wang, Z., Coburnb, C. A., Ren, X., \& Teillet, P. M. (2012). Effect of soil surface roughness and scene components on soil surface bidirectional reflectance factor. Canadian Journal of Soil Science, 92, 297-313. 
Wu, C. Y., Niu, Z., \& Wang, J. D. (2010). Predicting leaf area index in wheat using angular vegetation indices derived from in situ canopy measurements. Canada Journal of Remote Sensing, 36(4), 301-312.

Xue, L. H., Cao, W. X., Luo, W. H., Dai, T. B., \& Zhu, Y. (2004). Monitoring leaf nitrogen status in rice with canopy spectral reflectance. Agronomy Journal, 96(1), 135-142.

Yang, M. H., Liu, L. Y., Liu, T. J., Huang, W. J., \& Zhao, C. J. (2002). Research on a method to retrieve biophysical and biochemical parameters of wheat canopy with hyperspectral remote sensing. Acta Geodaetica et Cartographica Sinica, 31(4), 316-321. (in Chinese).

Zhu, Y., Li, Y., Feng, W., Tian, Y., \& Cao, W. (2006). Monitoring leaf nitrogen in wheat using canopy reflectance spectra. Canadian Journal of Plant Science, 86, 1037-1046. 